\title{
Leptospirosis Outbreak after a Heavy Rainfall Typhoon in the Philippines: Clinical Features, Outcome and Prognostic Factors for Mortality
}

\author{
Evalyn A. Roxas, ${ }^{1,2}$ Marissa M. Alejandria, ${ }^{2,3,4}$ Myrna T. Mendoza, $, 2,5$ \\ Arthur Dessi E. Roman,2,6 Katerina T. Leyritana² and Joann Kathleen B. Ginete-Garcia ${ }^{5}$ \\ ${ }^{1}$ Department of Medical Microbiology, College of Public Health, University of the Philippines Manila \\ 2Section of Infectious Diseases, Department of Medicine, College of Medicine and Philippine General Hospital, University of the Philippines Manila \\ ${ }^{3}$ Department of Clinical Epidemiology, College of Medicine, University of the Philippines Manila \\ ${ }^{4}$ The Medical City \\ ${ }^{5}$ National Kidney and Transplant Institute \\ ${ }^{6}$ Manila Doctors Hospital
}

\begin{abstract}
Background and Objectives. In September 2009, Metro Manila was hit by a heavy rainfall typhoon Ketsana inundating several cities of Metro Manila causing an outbreak of leptospirosis. We analyzed the prognostic factors associated with mortality among leptospirosis patients admitted after the typhoon at nine tertiary hospitals from September to November 2009.
\end{abstract}

Methods. We reviewed the charts of patients with probable and confirmed leptospirosis. Confirmed leptospirosis was based on any of the following: positive leptospiral culture of blood or urine, single high leptospira microagglutination titer (MAT) of $1: 1600$ or a fourfold rise in MAT antibody titers or seroconversion. Patients with negative serology or cultures but with history of wading in floodwaters plus any of the following signs and symptoms: fever, headache, myalgia, conjunctival suffusion, diarrhea and abdominal pain, jaundice, oliguria and changes in sensorium were considered probable cases.

Results. We analyzed 332 probable and 259 confirmed leptospirosis patients. Mean age was $37.95 \pm 14.09$, mostly males $(80.2 \%)$. Almost all patients $(98 \%)$ waded in floodwaters. Majority had moderate to severe form of leptospirosis (83\%). Acute renal failure was the most common complication (87.1\%). Mortality was $11.3 \%$ mostly due to pulmonary hemorrhage. On multivariate analysis of confirmed and probable cases, the factors independently associated with mortality were pulmonary

Presented at the 12th Western Pacific Conference on Chemotherapy and Infectious Diseases, December 2010, Singapore (Oral Presentation) and the Infectious Diseases Society of America Convention, October 2010, Canada (Poster Presentation). It has won 2nd place at the Philippine Society for Microbiology and Infectious Diseases Research Forum, November 2010, Crowne Plaza, and 2nd place at the Department of Medicine-UP-PGH Research Forum, October 2010, UP-PGH.

Corresponding author: Evalyn A. Roxas, MD

Department of Medical Microbiology

College of Public Health

University of the Philippines Manila

625 Pedro Gil St., Ermita, Manila 1000 Philippines

Telephone: +6325255874

Email: earoxas1@up.edu.ph hemorrhage (OR $2.75,95 \% \mathrm{Cl} 1.46$ to 5.20 ), severity of the disease (OR 3.85, 95\% Cl 1.60 to 9.26), thrombocytopenia (OR $3.16,95 \% \mathrm{Cl} 1.22-8.16)$, duration of illness before admission (OR $0.88,95 \% \mathrm{Cl} 0.78-0.99$ ) and age (OR $1.03,95 \% \mathrm{Cl} 1.00-1.06)$.

Conclusion. Pulmonary hemorrhage remains a poor prognostic factor and strong predictor of mortality among patients with severe leptospirosis. Early consult through heightened awareness of the public and prompt recognition of leptospirosis among clinicians can decrease the risk for progression to complications of leptospirosis and mortality.

Key Words: leptospirosis, clinical profile, predictors of mortality, typhoon, Philippines, outbreak

\section{Introduction}

Leptospirosis has been recognized as an important global public health problem because of its ability to cause disease in epidemic proportions. Increasing incidence in both developing and developed countries has been reported. ${ }^{1}$ Wild and domestic animals act as reservoirs that contaminate the human environment making it an endemic zoonosis. Traditionally considered an occupational risk among persons exposed to contaminated water or infected animal urine, leptospirosis has re-emerged as a major public health concern, particularly in the tropics. ${ }^{2}$ Flooding is recognized as a factor increasing the risk for exposure to leptospires through contact with contaminated water or mud. ${ }^{3}$ Urban outbreaks of leptospirosis usually cluster in areas with poor sanitation and that remained flooded for quite a time post heavy rainfall. ${ }^{3}$ Recent outbreaks after flooding from heavy rainfall raised awareness on the risk of leptospirosis in disaster situations.

On September 26, 2009, typhoon Ketsana (local name Ondoy) hit Metro Manila with heavy rainfall of $455 \mathrm{~mm}$ in just 24 hours inundating several cities and municipalities, which was significantly heavier than the recorded average rainfall of 965 t0 4,064 mm per year in the Philippines. Four weeks later, Metro Manila and some surrounding provinces remained underwater. On the average, 680 leptospirosis 
cases and 40 deaths from the disease are reported in the Philippines every year. However, following the heavy rainfall in 2009, an increase of 2,292 suspected cases of leptospirosis with 178 deaths $(7.8 \%)$ were recorded two weeks after the typhoon prompting the Department of Health to declare a leptospirosis outbreak. ${ }^{4}$

Leptospirosis is an acute febrile illness usually presenting with mild nonspecific symptoms but can also have severe fatal complications sometimes. Progression of the disease from mild to severe state can sometimes be fast and irreversible. Subclinical cases are usually very mild, flulike illnesses with patients recovering spontaneously. Those with the severe form develop complications involving various organs and requiring hospitalization. International studies on clinical profile of leptospirosis patients after flooding were reported ${ }^{5-8}$ while local studies on the clinical presentation of leptospirosis patients were done previously but not during an outbreak. ${ }^{9-11}$

We conducted this retrospective observational cohort study to determine the prognostic factors associated with mortality and to describe the clinical features and outcomes of leptospirosis patients after the heavy rainfall typhoon Ondoy. Data derived from this study can be used to guide clinicians in the early recognition and management of leptospirosis during the monsoon months to prevent complications, which can lead to severe morbidity and mortality.

\section{Methods}

\section{Setting and Study Population}

Patients suspected of leptospirosis admitted from September 28, 2009 to November 30, 2009 to the following hospitals proximal to the major cities flooded by the typhoon were included: University of the Philippines-Philippine General Hospital (UP-PGH), National Kidney and Transplant Institute (NKTI), The Medical City (TMC), University of Santo Tomas Hospital (USTH), Manila Doctors Hospital $(\mathrm{MDH})$, Ospital ng Maynila Medical Center (OMMC), Cardinal Santos Medical Center (CSMC), East Avenue Medical Center (EAMC) and Makati Medical Center (MMC).

The demographic profile, signs and symptoms and clinical course of the patients were obtained through patient interview and chart review. History of wading in flood waters, ingestion of floodwater and flood-related injuries were also asked. All data were recorded in a standardized case report form.

\section{Criteria for probable leptospirosis}

Patients with history of wading in floodwater plus any of the following signs and symptoms: fever, headache, myalgia, conjunctival suffusion, diarrhea and abdominal pain, jaundice, decreased urine output and changes in sensorium/meningism were assessed to have probable leptospirosis.

\section{Confirmed Cases}

Using the WHO criteria of definitive leptospirosis, laboratory confirmation of the diagnosis was based on any of the following: a) positive leptospiral culture of the blood and/or urine; b) single high leptospira microagglutination titer (MAT) of $\geq 1$ : 1600 from blood extracted any time during admission; c) seroconversion from initial negative to a positive antibody titer on second sample; d) fourfold rise in antibody titers by MAT from acute to convalescent. To determine the acute titer, blood was extracted upon consult or admission. Then blood was extracted again 7-10 days after the first extraction or just before discharge to determine the convalescent titer. All culture and serologic examination for leptospirosis were done in a single laboratory, the UPPGH IDS laboratory.

\section{Data Analysis}

Descriptive data were summarized using frequencies and percentages for categorical data. For continuous data, means and standard deviation were computed. Bivariate and multivariable logistic regression analyses were performed to determine the prognostic factors associated with mortality using the Statistical Package for the Social Sciences (SPSS Version 17, Chicago Ill) software. Odds ratios with $95 \%$ CI were reported.

To determine the factors associated with mortality with an odds ratio of 2, an estimated mortality of $15-25 \%$, precision of $5 \%$ and $80 \%$ power, 450 confirmed cases of leptospirosis were needed.

\section{Ethical considerations}

This study was technically and ethically approved by the Ethics Review Board of the Philippine General Hospital, University of the Philippines Manila (Ref No. MED 2009-1110-119; 2009 Dec 21).

\section{Results}

Out of 670 possible leptospirosis patients who consulted and/or were admitted in the nine tertiary hospitals in Metro Manila between September 28, 2009 and November 30, 2009 after the typhoon Ondoy, 591 suspected leptospirosis cases were included in the study. We excluded 79 patients who either had no laboratory specimens sent or no available clinical data.

Of the 591 suspected leptospirosis cases, 259 were confirmed by serology and/or culture and 332 were probable leptospirosis. Table 1 is a summary of the demographic characteristics and distribution of the patients included in this study. Majority were men with mean age of 37.95 (SD 14.09) years. The patients who died were statistically significantly older with mean age of 41 years old compared to those who survived with mean age of 37 years. Sex distribution and the proportion of patients with comorbidities did not differ significantly between those who survived and those who 
died. Almost all of the cases had a history of wading or swimming in floodwaters (98\%). A small percentage also swallowed floodwaters, had open wounds which served as point of entry of the leptospires or were exposed to animal carcasses in the floodwaters. Most patients came from Rizal (18\%), followed by Quezon City (14\%), Manila (12\%), Makati
(12\%) and Marikina (12\%). More patients consulted and eventually were admitted during the first week of illness (33\%). Of the nine participating tertiary hospitals, UPPhilippine General Hospital had the most number of cases (30\%) followed by the National Kidney and Transplant Institute (25.4\%) and The Medical City (9\%) (Table 1).

Table 1. Demographic profile and distribution of leptospirosis cases

\begin{tabular}{|c|c|c|c|c|}
\hline \multirow{3}{*}{ Characteristic } & \multicolumn{2}{|c|}{ Confirmed and probable cases of leptospirosis } & \multirow{3}{*}{ Total N=591 } & \multirow{3}{*}{$\mathrm{p}$ value } \\
\hline & \multicolumn{2}{|c|}{$\mathrm{N}=591$} & & \\
\hline & Survived $\mathrm{n}=524(\%)$ & Died $n=67(\%)$ & & \\
\hline \multicolumn{5}{|l|}{ Age (Yrs) } \\
\hline Mean \pm SD & $37.65 \pm 14.05$ & $41.25 \pm 13.10$ & $37.95 \pm 14.09$ & 0.05 \\
\hline Range & $14-79$ & $19-60$ & $14-79$ & \\
\hline \multicolumn{5}{|l|}{ Sex } \\
\hline Male & $416(79.4)$ & $58(86.6)$ & $474(80.2)$ & 0.16 \\
\hline Female & 108 (20.6) & $9(13.4)$ & $117(19.8)$ & \\
\hline \multicolumn{5}{|l|}{ Occupation } \\
\hline Unemployed & $102(19.5)$ & $10(14.9)$ & $112(19.0)$ & \\
\hline Government employee & $39(7.4)$ & $1(1.5)$ & $40(6.8)$ & \\
\hline Laborers & $29(5.5)$ & $1(1.5)$ & $30(5.1)$ & \\
\hline Businessman & $21(4.0)$ & 0 & $21(3.6)$ & \\
\hline Student & $21(4.0)$ & $1(1.5)$ & $22(3.7)$ & \\
\hline Driver & $13(2.5)$ & $2(3.0)$ & $15(2.5)$ & \\
\hline Self employed & $13(2.5)$ & $2(3.0)$ & $15(2.5)$ & \\
\hline Teacher & $13(2.5)$ & 0 & $13(2.2)$ & \\
\hline House help & $11(2.1)$ & 0 & $11(1.9)$ & \\
\hline Vendor & $10(1.9)$ & 0 & $10(1.7)$ & \\
\hline With comorbidities & $47 \quad(9.0)$ & $2(3.0)$ & $49 \quad(8.3)$ & 0.09 \\
\hline \multicolumn{5}{|l|}{ Residence } \\
\hline Rizal & $93(17.7)$ & $15(22.4)$ & $108(18.3)$ & \\
\hline Quezon City & 73 (13.9) & $8(11.9)$ & $81(13.7)$ & \\
\hline Manila & $65(12.4)$ & $4(6.0)$ & $70(11.8)$ & \\
\hline Marikina & $62(11.8)$ & $5(7.5)$ & $66(11.2)$ & \\
\hline Makati & $56(10.7)$ & $12(17.9)$ & $68(11.5)$ & \\
\hline Pasig & $45(8.6)$ & $3(4.5)$ & $48(8.1)$ & \\
\hline Pasay & $22(4.2)$ & $1(1.5)$ & $23(3.9)$ & \\
\hline Taguig & $17(3.2)$ & $2(3.0)$ & $19(3.2)$ & \\
\hline Paranaque & $13(2.5)$ & $2(3.0)$ & $15 \quad(2.5)$ & \\
\hline Laguna & $12(2.3)$ & $4(6.0)$ & $16(2.7)$ & \\
\hline Bulacan & $9(1.7)$ & $1(1.5)$ & $10(1.7)$ & \\
\hline Mandaluyong & $9(1.7)$ & $2(3.0)$ & $11(1.9)$ & \\
\hline Cavite & $8(1.5)$ & $1(1.5)$ & $9(1.5)$ & \\
\hline Malabon & $4(0.8)$ & 0 & $4 \quad(0.7)$ & \\
\hline San Juan & $4(0.8)$ & $2(3.0)$ & $6(1.0)$ & \\
\hline Nueva Ecija & $3(0.6)$ & $2(3.0)$ & $5(0.8)$ & \\
\hline Valenzuela & $3(0.6)$ & $2(3.0)$ & $5(0.8)$ & \\
\hline Batangas & $3(0.6)$ & 0 & $3(0.5)$ & \\
\hline Pateros & $2(0.4)$ & 0 & $2(0.3)$ & \\
\hline Las Pinas & $2(0.4)$ & 0 & $2(0.3)$ & \\
\hline Waded / swam in floodwaters & $513(97.9)$ & $65(97.0)$ & $578(98.0)$ & 0.65 \\
\hline Swallowed floodwaters & $56(10.7)$ & $2(3.0)$ & $58(9.8)$ & 0.05 \\
\hline Presence of wound & $91(17.4)$ & $4(6.0)$ & $95(16.1)$ & 0.02 \\
\hline Exposure to animal carcass & $35(6.7)$ & $4(6.0)$ & $39(6.6)$ & 1.00 \\
\hline \multicolumn{5}{|c|}{ Duration of Illness before admission } \\
\hline$<7$ days & $186(35.5)$ & $10(14.9)$ & $196(33.2)$ & \\
\hline$>7$ days & $54(10.3)$ & $3(4.5)$ & $57(9.6)$ & \\
\hline \multicolumn{5}{|l|}{ Hospital } \\
\hline UP-PGH & $162(30.9)$ & $17(25.4)$ & $179(30.3)$ & \\
\hline NKTI & $130(24.8)$ & $20(29.9)$ & $150(25.4)$ & \\
\hline The Medical City & $52(9.9)$ & $2(3.0)$ & $54 \quad(9.1)$ & \\
\hline UST Hospital & $20(3.8)$ & $2(3.0)$ & $22(3.7)$ & \\
\hline Manila Doctors Hosp & $13(2.5)$ & 0 & $13(2.2)$ & \\
\hline Ospital ng Maynila & $13(2.5)$ & 0 & $13(2.2)$ & \\
\hline Cardinal Santos MC & $5(1.0)$ & 0 & $5(0.9)$ & \\
\hline East Av Med Center & $80(15.3)$ & $2(3.0)$ & $82(13.9)$ & \\
\hline Makati Medical Center & $11(2.1)$ & $1(1.5)$ & $12(2.0)$ & \\
\hline
\end{tabular}


Majority of the confirmed leptospirosis cases had positive serology (68\%). Single high MAT titers were seen in $49 \%, 13 \%$ had a four-fold rise while $6 \%$ had seroconversion. Of the 259 confirmed leptospirosis, 55 (21\%) had positive leptospiral blood culture and only two patients had positive urine culture. Ten percent were positive on both serology and culture (Table 2).

Table 2. Laboratory confirmed leptospirosis cases

\begin{tabular}{|c|c|}
\hline Laboratory Diagnosis & Number $n=259(\%)$ \\
\hline Positive Culture & $57(22.0)$ \\
\hline Blood cultures & $55(21.2)$ \\
\hline Urine cultures & $2(0.8)$ \\
\hline Serology & $176(68.0)$ \\
\hline Single high titer & $127(49.0)$ \\
\hline Fourfold rise & $33(13.0)$ \\
\hline Seroconversion & $16(6.1)$ \\
\hline Positive Serology and Culture & $26(10.0)$ \\
\hline
\end{tabular}

\section{Clinical and Laboratory Features}

Fever was the most common presenting symptom followed by myalgia and/or calf tenderness, malaise and headache. Conjunctival suffusion was seen in more than half of the patients (53.1\%). Twenty percent of the patients came in hypotensive and the proportion of patients with hypotension was significantly greater in the mortality group compared to the group that survived. Gastrointestinal symptoms reported were abdominal pain $(56.8 \%)$, nausea and vomiting (49\%), diarrhea $(38.6 \%)$, and jaundice $(29.9 \%)$. Pulmonary signs and symptoms included cough $(27.6 \%)$, dyspnea $(17.8 \%)$, crackles $(19.3 \%)$, and hemoptysis (11.8\%). Oliguria was present in 51\%. Bleeding tendencies such as hematuria was seen in $19.8 \%$, gastrointestinal bleeding in $12.5 \%$ and other hemorrhagic signs like epistaxis or petechiae in $12.7 \%$. The proportion of patients presenting with hypotension, jaundice, oliguria, dyspnea and rales on auscultation were significantly greater among those who died compared to the patients who survived (Table 3).

More than half of the study population (58.4\%) had elevated creatinine. Thrombocytopenia or platelet count of $<100,000 / \mathrm{mm} 3$ was present in only $17 \%$. Leukocytosis was more commonly seen in $40.3 \%$ of patients. Only $23 \%$ had an elevated serum AST level and a smaller percentage (14.2\%) had hyperkalemia. There were significantly more patients with azotemia, defined as elevated creatinine level of $>176$ umol/L, and thrombocytopenia among those who died compared to those who survived (Table 3).

Table 3. Clinical and laboratory features of leptospirosis cases

\begin{tabular}{|c|c|c|c|c|}
\hline \multicolumn{5}{|c|}{ Confirmed and probable cases of leptospirosis } \\
\hline \multirow[t]{2}{*}{ Clinical features } & \multicolumn{2}{|c|}{$\mathrm{N}=591$} & \multirow[t]{2}{*}{ Total N=591 } & \multirow[t]{2}{*}{$\mathrm{p}$ value } \\
\hline & Survived $n=524(\%)$ & Died $n=67(\%)$ & & \\
\hline \multicolumn{5}{|l|}{ Non-specific } \\
\hline Fever & $495(94.5)$ & $55(82.1)$ & $550(93.1)$ & 0.0009 \\
\hline Myalgia/calf tenderness & $369(70.4)$ & $38(56.7)$ & 407 (68.9) & 0.02 \\
\hline Malaise & $362(69.1)$ & $43(64.2)$ & $405(68.5)$ & 0.42 \\
\hline Headache & $273(52.1)$ & $22(32.8)$ & $295(49.9)$ & 0.003 \\
\hline Chills & $211(40.3)$ & $17(25.4)$ & $228(38.6)$ & 0.02 \\
\hline Conjunctival suffusion & $284(54.2)$ & $30(44.8)$ & $314(53.1)$ & 0.15 \\
\hline Hypotension & $93(17.7)$ & $24(35.8)$ & $117(19.8)$ & 0.0005 \\
\hline \multicolumn{5}{|l|}{ Gastrointestinal } \\
\hline Abdominal pain & $300(57.3)$ & $36(53.7)$ & $336(56.8)$ & 0.58 \\
\hline Nausea/Vomiting & $259(49.4)$ & $32(47.8)$ & $291(49.2)$ & 0.80 \\
\hline Diarrhea & $206(34.9)$ & $22(32.8)$ & $228(38.6)$ & 0.30 \\
\hline Jaundice & $146(27.8)$ & $31(46.3)$ & 177 (29.9) & 0.002 \\
\hline GI bleeding & $66(12.6)$ & $8(11.9)$ & $74(12.5)$ & 0.88 \\
\hline \multicolumn{5}{|l|}{ Renal } \\
\hline Oliguria & $260(49.6)$ & $42(62.7)$ & $302(51.1)$ & 0.04 \\
\hline Hematuria & $104(19.8)$ & $13(19.4)$ & $117(19.8)$ & 0.93 \\
\hline \multicolumn{5}{|l|}{ Pulmonary } \\
\hline Cough & $149(28.4)$ & $14(20.9)$ & $163(27.6)$ & 0.19 \\
\hline Dyspnea & 87 (16.6) & $18(26.9)$ & $105(17.8)$ & 0.04 \\
\hline Crackles/rales & $86(16.4)$ & $28(41.8)$ & $114(19.3)$ & $<0.0001$ \\
\hline Hemoptysis & $61(11.6)$ & $9(13.4)$ & $70(11.8)$ & 0.67 \\
\hline \multicolumn{5}{|l|}{ Hematologic } \\
\hline Hemorrhagic signs (epistaxis, petechiae) & $62(11.8)$ & $13(19.4)$ & $75(12.7)$ & 0.08 \\
\hline \multicolumn{5}{|l|}{ Laboratory } \\
\hline Elevated CREA (>176umol/L) & $291(55.5)$ & $54(80.6)$ & $345(58.4)$ & 0.0001 \\
\hline Leukocytosis (wbc $>12,000)$ & $204(38.9)$ & $34(50.7)$ & $238(40.3)$ & 0.06 \\
\hline Elevated BUN (>10-20mg/dL) & $129(24.6)$ & $10(14.9)$ & $139(23.5)$ & 0.08 \\
\hline Elevated AST (> 37 SI Units) & $121(23.1)$ & $13(19.4)$ & $134(22.7)$ & 0.50 \\
\hline Thrombocytopenia $(<100,000 / \mathrm{mm} 3)$ & 75 (14.3) & $27(40.3)$ & $102(17.3)$ & $<0.0001$ \\
\hline Elevated serum $K(>4)$ & $71(13.6)$ & $13(19.4)$ & $84(14.2)$ & 0.20 \\
\hline
\end{tabular}


Outcomes of Confirmed Leptospirosis

Majority of the patients had moderate to severe form of leptospirosis (83\%). Moderate to severe leptospirosis refer to patients with any of the following: beginning renal failure (azotemia, decreased urine output), dyspnea with or without need for oxygen support, basal infiltrates on chest X-ray, conjunctival suffusion, abdominal pain, and meningismus. ${ }^{12}$ Acute renal failure $(87.1 \%)$ was the most common complication of leptospirosis in this study. Pulmonary hemorrhage was reported in $5.2 \%$ of the population, while myocarditis and meningitis in $2.7 \%$ and $2.4 \%$, respectively. Nevertheless, majority of the patients were discharged improved (95\%). The proportion of patients with acute renal failure on admission and pulmonary hemorrhage were significantly greater among those who died compared to those who survived (Table 4).

The mortality rate of leptospirosis patients in this study was $11 \%$. Most of those who died had renal failure upon admission (82.1\%). Weil's syndrome, the most distinctive form of severe leptospirosis characterized by impaired hepatic and renal function with signs of hemorrhage, ${ }^{12}$ was seen in $33 \%$ of the mortalities. In addition, almost $25 \%$ of those who died presented with pulmonary hemorrhage (Table 4).

Table 4. Complications of leptospirosis

\begin{tabular}{|c|c|c|c|c|}
\hline \multicolumn{5}{|c|}{ Confirmed and probable cases of leptospirosis } \\
\hline & \multicolumn{2}{|c|}{$N=591$} & \multirow[t]{2}{*}{ Total N=591 } & \multirow[t]{2}{*}{$\mathrm{p}$ value } \\
\hline & Survived $\mathrm{n}=524(\%)$ & Died n= $67(\%)$ & & \\
\hline Renal Failure & $459(87.6)$ & $56(83.6)$ & $515(87.1)$ & \\
\hline upon admission & $348(66.4)$ & $55(82.1)$ & $403(68.2)$ & 0.0001 \\
\hline progression & $39(7.4)$ & $8(11.9)$ & $47(8.0)$ & 0.16 \\
\hline Pulmonary hemorrhage & $14(2.7)$ & $17(25.4)$ & $31(5.2)$ & $<0.0001$ \\
\hline Meningitis & $11(2.1)$ & $3(4.5)$ & $14(2.4)$ & 0.23 \\
\hline Myocarditis & $11(2.1)$ & $1(1.5)$ & $12(2.0)$ & 0.34 \\
\hline Weil's Disease & $166(31.7)$ & $22(32.8)$ & $188(31.8)$ & 0.85 \\
\hline
\end{tabular}

Table 5. Predictors of mortality among confirmed and probable cases: multivariate analysis

\begin{tabular}{|c|c|c|c|c|}
\hline Risk Factor & OR $(95 \% \mathrm{CI})$ for confirmed and probable cases & p-value & OR $(95 \% \mathrm{CI})$ for confirmed cases & p-value \\
\hline Age & $1.03(1.00,1.06)$ & 0.04 & $2.42(0.58,10.10)$ & 0.22 \\
\hline Sex & $1.33(0.49,3.63)$ & 0.58 & -- & -- \\
\hline Exposure to flood & $0.29(0.02,4.04)$ & 0.36 & -- & -- \\
\hline $\begin{array}{l}\text { Days of illness before admission } \\
\text { (>7days) }\end{array}$ & $0.88(0.78,0.99)$ & 0.03 & -- & -- \\
\hline Presence of comorbidities & $0.42(0.11,1.57)$ & 0.20 & $0.94(0.14,6.19)$ & 0.95 \\
\hline Thrombocytopenia & $3.16(1.22,8.16)$ & 0.02 & $1.70(0.36,8.08)$ & 0.50 \\
\hline Renal dysfunction & $0.73(0.20,2.61)$ & 0.62 & -- & -- \\
\hline Pulmonary hemorrhage & $2.75(1.46,5.20)$ & 0.002 & $77.0(12.84,462)$ & $<0.001$ \\
\hline Severity of the disease & $3.85(1.60,9.26)$ & 0.003 & -- & -- \\
\hline Myocarditis & -- & -- & $2.46(0.13,45.48)$ & 0.54 \\
\hline Weil's syndrome & -- & -- & $0.72(0.12,4.33)$ & 0.72 \\
\hline
\end{tabular}

Table 6. Predictors of pulmonary hemorrhage

\begin{tabular}{llll}
\hline Risk Factor & OR & $\mathbf{9 5 \%}$ CI & p-value \\
\hline Age & 1.7 & $0.64-4.47$ & 0.29 \\
Sex & 0.67 & $0.13-3.41$ & 0.63 \\
Oliguria & 1.82 & $0.51-6.51$ & 0.36 \\
Hemoptysis & 2.35 & $0.76-7.27$ & 0.14 \\
Hypotension & 6.05 & $2.10-17.37$ & 0.001 \\
Jaundice & 2.33 & $0.79-6.88$ & 0.13 \\
Thrombocytopenia & 1.11 & $0.35-3.48$ & 0.86 \\
Elevated creatinine & 2.66 & $0.52-13.55$ & 0.24 \\
\hline
\end{tabular}

On multivariate analysis, the independent predictors of mortality for confirmed and probable cases were age (OR 1.03, 95\% CI 1.00-1.06), pulmonary hemorrhage (OR 2.75, 95\% CI 1.46 to 5.20 ), severity of the disease (OR $3.85,95 \%$ CI 1.60 to 9.26) and thrombocytopenia (OR 3.16, 95\% CI 1.22-8.16). On the other hand, consultation 7 days or more from the duration of illness before admission was associated with improved survival (OR 0.88, 95\% CI 0.78-0.99). On sensitivity analysis of confirmed cases, only pulmonary hemorrhage remained independently associated with mortality (OR 77, 95\% CI 12.8 to 462) (Table 5). On further analysis on the predictors of pulmonary hemorrhage, hypotension was identified as independently associated with development of pulmonary hemorrhage (OR 6.05, 95\% CI 2.10 to 17.37) (Table 6).

\section{Discussion}

This large cohort of moderate to severe leptospirosis provides comprehensive data on the clinical course, outcome and predictors of mortality among cases observed during an outbreak from an unusually heavy rainfall from Typhoon Ketsana that hit Metro Manila. Previous studies done in the country were mostly single center studies describing the clinical features and outcomes of seasonal leptospirosis. Our cohort included a purposive sample of patients from almost all areas of Metro Manila admitted in nine hospitals proximal to the areas affected by the typhoon. In the Philippines, few studies reported factors associated with mortality of 
leptospirosis (Table 7). This leptospirosis outbreak cohort of 2009 recorded a mortality rate of $11 \%$ which is within the reported range of mortality rates of leptospirosis from 5\% to $40 \% .^{13}$ Since this study was conducted in a hospital setting, we expected a high representation of patients with severe disease. Interestingly, the non-specific prodromal symptoms of fever, headache, malaise, myalgia and calf tenderness were more commonly reported among the patients who survived compared to those who died. As expected, the signs of severity were more commonly observed among those who died, i.e., hypotension on admission, oliguria, jaundice, dyspnea and crackles on auscultation, elevated creatinine and thrombocytopenia.

The earlier cohorts on seasonal leptospirosis at the Philippine General Hospital identified oliguria as a significant predictor of mortality with oliguric patients having twice the risk of dying than non-oliguric patients. ${ }^{14}$ Elevated creatinine, low platelet count, low $\mathrm{HCO}$, low alkaline phosphatase and type of treatment received (dopa-furo-mannitol vs dopa-furo among oliguric patients) were the identified predictors of oliguria and eventually mortality. ${ }^{15} \mathrm{~A}$ smaller cohort of presumptive leptospirosis patients in another government hospital described that all patients who died had oliguric renal failure. Mortality rate was $18 \%$ and factors associated with mortality on univariate analysis were leukocytosis, thrombocytopenia, evidence of bleeding, oliguria, length of time from onset of disease up to the time the patient sought consult and evidence of liver dysfunction. ${ }^{16}$

In contrast to the earlier single-center studies on seasonal leptospirosis that reported factors associated with mortality, our study identified pulmonary hemorrhage as a strong independent predictor of mortality (Table 7). Although earlier studies did report pulmonary hemorrhage ${ }^{17}$ and acute renal failure ${ }^{18}$ among the most common causes of death in leptospirosis, no further analysis was done. One descriptive study observed that mortality was higher in the thrombocytopenic group with hemorrhagic causes. ${ }^{17}$

The incidence of pulmonary involvement in leptospirosis varies from $20 \%$ to $70 \% .^{19}$ Pulmonary manifestations were previously reported to be less prominent with hemoptysis being observed in 3-25\% of patients and chest pain in 10\%. ${ }^{19}$ Epidemic cohorts of leptospirosis in other countries have reported pulmonary manifestations dominating the clinical picture. These cohorts have also identified pulmonary hemorrhage as a significant predictor of mortality (Table 8).

Table 7. Comparison of local studies that reported factors associated with mortality of leptospirosis

\begin{tabular}{|c|c|c|c|c|}
\hline & $\begin{array}{c}\text { Edmilao }^{14} \\
1995 \\
\end{array}$ & $\begin{array}{c}\text { Villela }^{15} \\
2000 \\
\end{array}$ & $\begin{array}{c}\text { Orpilla-Bautista }^{16} \\
2002 \\
\end{array}$ & This study \\
\hline No. of leptospirosis cases & 191 & 300 & 83 & 591 \\
\hline No. of deaths & $16 / 191(8.5 \%)$ & $52 / 300(17 \%)$ & $15 / 83(18 \%)$ & $67 / 591(11.3 \%)$ \\
\hline \multirow[t]{6}{*}{ Prognostic factors of mortality } & Oliguria & Oliguria & Leukocytosis & Age \\
\hline & & Type of treatment received & Thrombocytopenia & Thrombocytopenia \\
\hline & & Low $\mathrm{HCO} 3$ & Evidence of bleeding & Pulmonary hemorrhage \\
\hline & & Low AlkPhos & Oliguria & Severity of the disease \\
\hline & & High creatinine & Delayed consultation ( $>6$ days) & \\
\hline & & Low platelet count & & \\
\hline
\end{tabular}

Table 8. Predictors of mortality in leptospirosis compared with cohorts from other countries

\begin{tabular}{|c|c|c|c|c|c|c|c|}
\hline & $\begin{array}{c}\text { France }^{20} \\
1997 \\
\end{array}$ & $\begin{array}{c}\text { Brazil }^{21} \\
1999\end{array}$ & $\begin{array}{c}\text { India }^{22} \\
2004 \\
\end{array}$ & $\begin{array}{c}\text { Brazil }^{23} \\
2008 \\
\end{array}$ & $\begin{array}{c}\text { Indonesia }^{24} \\
2009 \\
\end{array}$ & $\begin{array}{c}\text { India }^{25} \\
2014 \\
\end{array}$ & $\begin{array}{l}\text { This Study } \\
\text { Philippines }\end{array}$ \\
\hline $\begin{array}{l}\text { No. of lepto- } \\
\text { spirosis cases }\end{array}$ & 68 & 110 & 282 & 840 & 55 & 101 & 591 \\
\hline No. of deaths & $12(18 \%)$ & $24(22 \%)$ & $17(6.03 \%)$ & $119(17 \%)$ & $8(14.5 \%)$ & $17(16.8 \%)$ & $67 / 591(11.3 \%)$ \\
\hline \multirow{11}{*}{$\begin{array}{l}\text { Prognostic } \\
\text { factors of } \\
\text { mortality }\end{array}$} & Dyspnea & Oliguria & Lung in- & Age $>40$ years & Pulmonary & High aspar- & Age \\
\hline & (OR 11.7; CI 2.8-48.5) & (OR 9.0; CI & volvement & (OR 2.2; CI 1.1-4.3) & involvement & tate/alanine & Days of illness \\
\hline & Oliguria & $1.81-44.6)$ & $\begin{array}{l}\text { (OR 5.3; CI } \\
1.25-22.67 \text { ) }\end{array}$ & Pulmonary & $\begin{array}{l}\text { (OR 9.9;CI } \\
1.17-84.03)\end{array}$ & $\begin{array}{l}\text { aminotransfer- } \\
\text { ase ratio (AAR) }\end{array}$ & $\begin{array}{l}\text { before admission } \\
(>7 d)\end{array}$ \\
\hline & (OR 9; CI 2.1-37.9) & & Meningism & involvement & & (HR $1.208,95 \%$ & Thrombocyto- \\
\hline & Leukocytosis & & OOR 608. & (OR 6.0; CI 3.0-12.0) & & CI 1.05-1.39) & penia \\
\hline & (OR 2.5; CI 1.8-3.5) & & CI1.40-26.41) & Oliguria & & Delayed antibi- & Pulmonary \\
\hline & Abnormality on & & & (OR 3.0; CI 1.2-9.0) & & 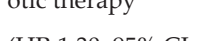 & hemorrhage \\
\hline & ECG finding & & & Platelets $<70,000$ & & $\begin{array}{l}\text { (HR } 1.30,95 \% \text { CI } \\
1.08-1.57)\end{array}$ & Severity of the \\
\hline & (OR 5.9; CI 1.4-24.8) & & & (OR 2.2; CI 1.2-4.7) & & & \\
\hline & $\begin{array}{l}\text { Alveolar infiltrates } \\
\text { on chest X-ray }\end{array}$ & & & $\begin{array}{l}\text { Creatinine }>3.0 \\
\mathrm{mg} / \mathrm{dL}\end{array}$ & & & \\
\hline & (OR 7.3; CI 1.7-31.7) & & & (OR 2.3; CI 1.1-5.) & & & \\
\hline
\end{tabular}


As early as 1997, in a study of 68 leptospirosis patients at the emergency department of West Indies, France, pulmonary manifestations such as dyspnea and alveolar infiltrates on chest radiographs were included in the five factors identified to be independently associated with mortality. ${ }^{20}$ In a retrospective cohort of patients with Weil's disease in Brazil, dyspnea, and pulmonary rales were also significant predictors of mortality on univariate analysis however on logistic regression, only oliguria was the identified independent factor associated with death. ${ }^{21}$ Moreover, another study reported lung involvement (dyspnea and hemoptysis) and central nervous system manifestation (meningism) as significant predictors of death among leptospirosis patients. ${ }^{22}$ In 2008, a case control study ascertaining prognostic factors associated with fatal outcomes in severe leptospirosis, concluded that pulmonary involvement was the strongest risk factor for death. ${ }^{23}$ Pulmonary involvement was also cited as strong predictor of mortality among 55 severe leptospirosis patients admitted at Dr. Sardjito Hospital, Yogyakarta, Indonesia from 2003 to $2007 .{ }^{24}$ A recent study in India, however, identified high aspartate/alanine transferase ratio and delayed antibiotic administration as significant predictors of mortality. ${ }^{25}$

Pulmonary hemorrhage is a consistent predictor of mortality as shown in previous studies. ${ }^{20,22-24}$ Acute respiratory distress syndrome is the usual complication of pulmonary hemorrhage and is the immediate cause of death of the patients. ${ }^{26}$ Leptospirosis patients who developed respiratory symptoms have high mortality rates ranging from $4.8 \%$ to $11 \% .{ }^{27}$ Hypotension was identified as a predictor of pulmonary hemorrhage in our cohort. Hypotension indicates impairment of the microcirculation and increased capillary permeability from vasculitis or even unrecognized bleeding. Vasculitis is the same pathogenesis for pulmonary hemorrhage in leptospirosis. Hence, presence of hypotension may indicate severe vasculitis and can predict impending pulmonary hemorrhage.

This large cohort of confirmed and probable cases of moderate to severe leptospirosis complements the results of previous cohorts of seasonal leptospirosis done in the country. The clinical findings in this outbreak compare very well with other local retrospective studies involving patients with seasonal leptospirosis. Acute renal failure and pulmonary hemorrhage were the two most common complications of the disease that influences survival. Prompt recognition and advances in the modalities for management of acute renal failure may have contributed to improved survival rates despite relatively delayed consultations of one week or more from onset of illness in this cohort. Our study identified pulmonary hemorrhage as a prognostic factor strongly associated with mortality in an outbreak setting.

\section{Conclusion}

The clinical manifestations and outcomes of leptospirosis in an outbreak setting did not vary significantly with seasonal-related leptospirosis. Pulmonary hemorrhage remains a poor prognostic factor and strong predictor for mortality among patients with severe leptospirosis. This emphasizes that, whether in seasonal cases or during outbreaks of leptospirosis, the need for awareness of the disease by the public and high index of suspicion for leptospirosis among clinicians are necessary to decrease morbidity and mortality.

Leptospirosis should always be included in the differential diagnosis of patients presenting with fever together with nonspecific prodromal symptoms following exposure to flood. Patients presenting with pulmonary manifestations, hypotension and oliguria should be monitored more closely and more aggressively.

We recommend molecular studies to determine whether the distribution of leptospirosis serovars and strains in the country has changed through the years in the current setting of climate change and whether these could have contributed to changes in the patterns of presentation and severity of the disease. Studies on the effectiveness of interventions to address pulmonary hemorrhage are also recommended.

\section{References}

1. Meites E, Jay MT, Deresinski S, et al. Reemerging Leptospirosis, California. Emerg Infect Dis. 2004; 10(3):406-12.

2. Flannery B, Costa D, Carvalho FP, et al. Evaluation of recombinant leptospira antigen - based enzyme - linked immunosorbent assays for the serodiagnosis of leptospirosis. J Clin Microbiol. 2001; 39(9):3303-10.

3. Gaynor K, Katz AR, Park SY, Nakata M, Clark TA, Effler PV. Leptospirosis on OAHU: an outbreak associated with flooding of a university campus. Am J Trop Med Hyg. 2007; 76(5):882-5.

4. Department of Health National Epidemiology Center Statistics.

5. Mathur M, De A, Turbadkar D. Leptospirosis outbreak in 2005: L.T.M.G. hospital experience. Indian J Med Microbiol. 2009; 27(2):153-5.

6. Bhardwaj P, Kosambiya JK, Desai VK. A case control study to explore the risk factors for acquisition of leptospirosis in Surat city, after flood. Indian J Med Sci. 2008; 62-11. 431-438.

7. Kawaguchi L, Sengkeopraseuth B, Tsuyuoka R, et al. Seroprevalence of leptospirosis and risk factor analysis in flood-prone rural areas in Lao PDR. Am J Trop Med Hyg. 2008; 78(6):957-61.

8. Lin PC, Chi CY, Ho MW, Chen CM, Ho CM, Wang JH. Demographic and clinical features of leptospirosis: three-year experience in central Taiwan. J Microbiol Immunol Infect. 2008; 41(2):145-50.

9. Alora B, Nambayan A, Perez J, Famatiga E, Alora A. Leptospirosis in Santo Tomas University Hospital: Analysis of 17 Cases, 1967-71. Phil J Microbiol Infect Dis. 1973; 2(1):11-22.

10. Mendoza MT, Tan S, Torres D, Tupasi TE. Human leptospirosis: Clinical and laboratory diagnosis. J Phil Med Assn. 1979; 5(6):219-24.

11. Marcial M, Dy E, Tan-Alora A. Leptospirosis revisited at the Santo Tomas University Hospital. Phil J Microbiol Infect Dis. 1994; 24(1):21-33.

12. Levett P, Haake D. Leptospirosis species (Leptospirosis). In: Mandell G, Bennett J, Dolin R, eds. Principles and practice of infectious diseases, $7^{\text {th }}$ ed. Philadelphia: Churchill Livingston Elsevier; 2010. pp. 3059-3065.

13. Lomar AV, Diament D, Torres JR. Leptospirosis in Latin America. Infect Dis Clin North Am. 2000; 14(1):23-39.

14. Edmilao MI, Lim A, Abalos M. Acute renal failure and mortality predictor factors in leptospirosis: a retrospective analysis. Phil J Intern Med. 1995; 33:189-99. 
15. Villela G, Edmilao MI, Cordero CP, Valdez JR. Predictors of oliguria and complications/mortality among patients with acute renal failure due to leptospirosis: a PGH experience. Phil J Intern Med. 2000; 38(5):235-42.

16. Orpilla-Bautista I, Panaligan, M. Predictors of Mortality among Patients with Leptospirosis Admitted at the JRRMMC. Phil J Microbiol Infect Dis. 2002; 31(4):145-9.

17. Casiple LC. Thrombocytopenia and bleeding in leptospirosis. Phil J Microbiol Infect Dis. 1998; 27(1):18-22.

18. Villanueva S, Dans A, Tanchuco J. Leptospirosis in the Philippine General Hospital: A review of initial presentation on admission 19801985. Acta Med Philipp. 1989; 143-7.

19. Divate SA, Chaturvedi R, Jadhav NN, Vaideeswar P. Leptospirosis associated with diffuse alveolar hemorrhage. J Postgrad Med. 2002; 48(2):131-2

20. Dupont H, Dupont-Perdrizet D, Perie JL, Zehner-Hansen S, Jarrige B, Daijardin JB. Leptospirosis prognostic factors associated with mortality. Clin Infect Dis. 1997; 25(3):720-4.

21. Daher E, Zanetta DM, Cavalcante MB, Abdulkader RC. Risk factors for death and changing patterns in leptospirosis acute renal failure. Am J Trop Med Hyg. 1999; 61(4):630-4.
22. Pappachan MJ, Mathew S, Aravindan KP, et al. Risk factors for mortality in patients with leptospirosis during an epidemic in northern Kerala. Natl Med J India. 2004; 17(5):240-2.

23. Spichler AS, Vilaça PJ, Athanazio DA, et al. Predictors of lethality in severe leptospirosis in urban Brazil. Am J Trop Med Hyg. 2008; 79(6):911-4.

24. Budiono E, Sumardi, Riyanto BS, Hisyam B, Hartopo AB. Pulmonary involvement predicts mortality in severe leptospirosis patients. Acta Med Indones. 2009; 41(1):11-4

25. Goswami RP, Goswami RP, Basu A, Tripathi SK, Chakrabarti S, Chattopadhyay I. Predictors of mortality in leptospirosis: an observational study from two hospitals in Kolkata, eastern India. Trans R Soc Trop Med Hyg. 2014; 108(12):791-6.

26. Doudier B, Garcia S, Quennee V, Jarno P, Brouqui P. Prognostic factors associated with severe leptospirosis. Clin Microbiol Infect. 2006; 12(4):299-300

27. Watt G, Padre LP, Tuazon M, Calubaquib C. Skeletal and cardiac muscle involvement in severe, late leptospirosis. J Infect Dis. 1990; 162(1):266-9.

\section{The}

\section{National Health Science Journal}

\author{
is now indexed in
}

\section{SciVerse Scopurso}

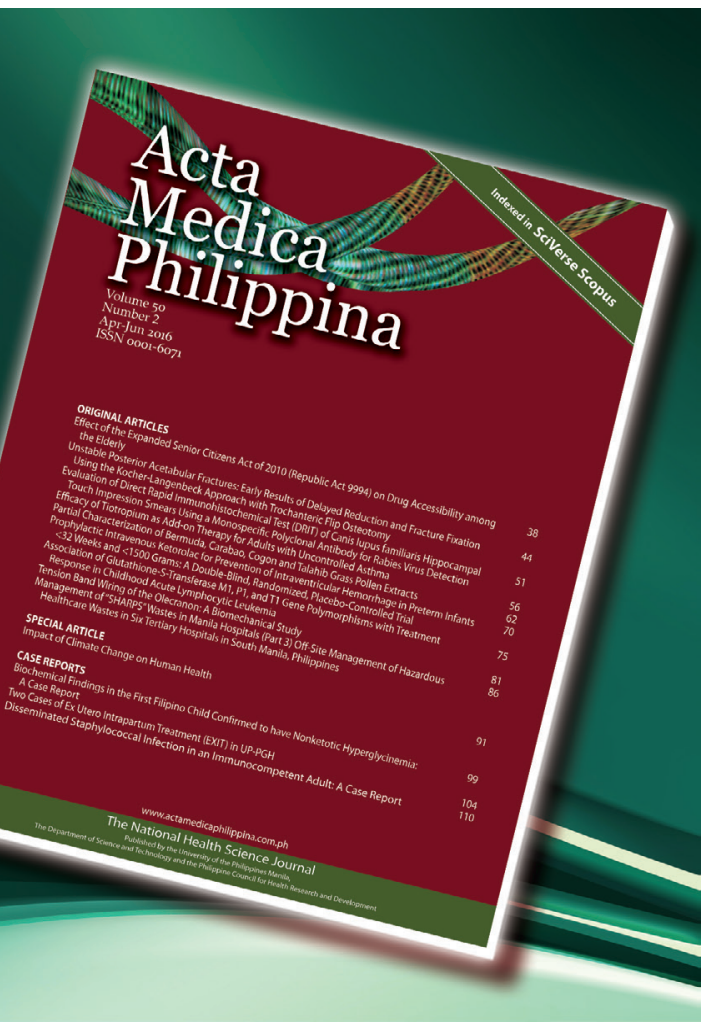

